Research Article

\title{
Numerical Analysis for the Caving Characteristics of Rock Mass with Inclined Joints in Caving Mining
}

\author{
Jinbo Sui, Fengyu Ren (D, Jianli Cao, and Huan Liu (iD) \\ School of Resources and Civil Engineering, Northeastern University, Shenyang 110819, China \\ Correspondence should be addressed to Huan Liu; gyliuhuan@163.com
}

Received 4 March 2021; Accepted 24 May 2021; Published 14 June 2021

Academic Editor: Rihong Cao

Copyright (c) 2021 Jinbo Sui et al. This is an open access article distributed under the Creative Commons Attribution License, which permits unrestricted use, distribution, and reproduction in any medium, provided the original work is properly cited.

In caving mining, the successful initiation and propagation of caving require one low-dip joint set. However, not every mine has a low-dip joint set. The Hemushan Iron Mine in China was taken as the engineering background, and the caving characteristics of rock mass with inclined joints were analyzed based on the synthetic rock mass (SRM) model. First, the inclined joints were investigated in the Hemushan Iron Mine. Second, model parameters were determined based on the geological conditions of the mine, and seven models were established. Third, the caving process was simulated, and caving characteristics were monitored. For rock mass with inclined joints after undercutting, the research showed that the crack zone was significant, and the crack zone existed not only around the undercut area but also further away in the model. The stress concentration areas dispersed in the model except for the top of the undercut area. The caving line was not a standard arch, and the highest point of the caving line was biased towards the direction of the undercut. Under the same undercut width, with the decrease of joint length in the joint system, the number of cracks decreased, the degree of stress concentration became weaker, and the height of the caving line decreased.

\section{Introduction}

Caving mining is a mining method used for underground mines. It refers to all mining operations in which the orebody caves naturally after undercutting [1]. Thus, the mining costs of caving mining are smaller than those of other mining methods. This method is of growing interest to companies concerned with the exploitation of massive orebodies because of its low cost [2]. However, theoretical and practical knowledge of caving characteristics, particularly in complex jointed rock masses, is also limited. The caving characteristics affect the mining design and even affect whether caving mining is suitable for a particular mine.

According to Brown [2], any unsupported rock mass will cave if it is undercut to a sufficient extent. Caving occurs as a result of gravity and induced stresses; the induced stresses are caused by undercut engineering or caving of rock mass. The process of caving depends on the relationships between the induced stresses, the strength of the rock mass, and the geometry and strengths of discontinuities in the rock mass. Kendorski [3] contended that the successful initiation and propagation of caving requires the presence of a well-developed, low-dip discontinuity set. The most ideal rock mass conditions for caving are at least two steep-dip discontinuity sets and one low-dip discontinuity set [2]. The steep-dip discontinuity sets provide the vertical displacement for caving. Duplancic and Brady [4] used a seismic monitoring system to study the early stages of caving and developed a conceptual model of caving. The model contains five regions: the caved zone, air gap, zone of discontinuous deformation, seismogenic zone, and surrounding rock mass. They also found that a flat-lying discontinuity set is required to act as a release mechanism for caving. Based on physical models and field observations, Cumming-Potvin et al. [5] also pointed out that the Duplancic model needs to be extended to include fracture banding. Jiang and Yang [6] performed a numerical simulation of caving characteristics and found that the stress balance arch formed in the orebody and stress concentration appeared at the arch foot. Song et al. [7] used boreholes to monitor the caving mechanism and determined that the caving height of rock strata is closely related to the rock mass quality and is seriously affected by the contact zone of rock strata. Zhang and Zhao [8] used RFPA software 
to study stope roof caving and concluded that the profile of the caved rock mass under high geostress changes gradually from a parabolic shape to a stratiform shape, while that with horizontal and vertical joints changes to a saddle shape and tower shape, respectively. In summary, the caving characteristics of jointed rock mass are complex, especially for different joint conditions. One of the conditions for caving is the existence of one low-dip discontinuity set; this condition is not found in many mines. Therefore, the caving characteristics with no discontinuity set with a low dip, such as those of inclined joints, also need to be studied.

At present, there are three main methods of studying caving characteristics. The first method is field tests in mining, such as seismic monitoring $[4,5,9,10]$. This method is not suitable for mines at the feasibility study stage or design stage, but it is suitable for monitoring the process of caving. The second method is the use of a physical model $[5,11-14]$ in the laboratory. This method has difficulty realizing the conditions of complex jointed rock mass, and it usually assumes that the rock mass is intact or simple (such as a coal seam). The third method is the numerical method, which is mainly based on the discrete-element method and finite-element method. $\mathrm{Nu}$ merical methods have rapidly developed and been applied in recent years because they can ensure the consistency of mechanical properties and simulate the complex conditions of a rock mass. Hassen et al. [15] analyzed an attentive caving phenomenon incorporating main geotechnical parameters based on the discrete-element method and finite-element method. Vyazmensky et al. [16] analyzed the interaction between block cave mining and a large overlying open pit by finite-element modeling/discrete-element modeling. Vakili and Hebblewhite [17] developed a new cavability assessment criterion for top-coal, and the discrete-element method was employed as the main analytical tool. Li et al. [18] investigated strata movement during the caving process based on a finite-element technique that incorporates an elasto-brittle fracture mechanics constitutive criterion. Cao et al. [19] simulated the ground settlement process caused by mining activity by the universal distinct-element code (UDEC). Paluszny and Zimmerman [20] simulated the growth of fractures around an undercut during caving by a finite-element-based method. Rafiee et al. [21] studied the influence parameters on the cavability of rock mass in block caving mines by using PFC3D software. Ren et al. [22] analyzed the damage evolution of a rock mass during caving and the surface subsidence mechanism based on RFPA2D. Eremin et al. [23] applied the finite-difference method and the continuum damage mechanics approach to simulate the stress-strain evolution of a rock mass on the underground opening during coal extraction. Each of the methods mentioned above has its own advantages and applicable conditions. However, the caving process of a rock mass is a dynamic and continuous process after undercutting. The crack distribution, stress distribution, and caving line are important components for the study of caving characteristics. Therefore, the numerical method is a good approach for studying the caving characteristics of jointed rock mass.
In this paper, taking the Hemushan Iron Mine in China as the engineering background, the caving characteristics of rock mass with inclined joints are investigated based on synthetic rock mass (SRM) models. A series of numerical models are compared and analyzed, and the characteristics of the crack distribution, stress distribution, and caving line are determined for a rock mass with inclined joints.

\section{Inclined Joints}

The Hemushan Iron Mine is an underground mine in China, located in Maanshan, Anhui Province. The orebody of the Hemushan Iron Mine is located in diorite and limestone, and its shape is lenticular and layered. As shown in Figure 1(a), the dip angle of the orebody is generally $45^{\circ}$ to $60^{\circ}$, the horizontal thickness is generally 10 to $85 \mathrm{~m}$, and the length is 130 to $335 \mathrm{~m}$ along the strike. In addition, the ore is mainly magnetic ore. At the $-150 \mathrm{~m}$ level, the strength of ore is low, and the stability of the orebody is poor. In this situation, it is difficult to form the ore drawing conditions and the bottom structure based on the original design of the sublevel open stope mining method, and this situation is suitable for caving mining.

The conditions of low ore strength and unstable orebody are advantageous for caving [1, 2, 24]. However, the occurrences of joints in the mine are investigated and analyzed. As shown in Figure 1(b), there are few low-dip joints in the mine, and the dominant joints are inclined. Therefore, it is necessary to study the caving characteristics of the inclined jointed rock mass and prevent potential safety hazards or ore loss and dilution in the mine.

\section{Methodology}

The initiation and propagation of caving may be caused by the following three reasons: rock blocks become free to fall under the influence of gravity, large rocks are broken and become free to fall under induced stresses and gravity, or rock blocks become free to slide on the joint under induced stresses and gravity. Therefore, the numerical method of the particle flow code was selected since it could be used to study intact rock, jointed rock mass, and large displacements of rock blocks.

The particle flow code provides an embodiment of the distinct-element method [25]. It consists of bodies (particles, clumps, and walls) and mechanical contacts (contact models). A body is composed of one or more constituent pieces that make up the body surface. The particles are rigid bodies with finite mass that move independently of one another and can both translate and rotate. The interaction between particles occurs through internal forces and moments. Contact mechanics is embodied in particle-interaction laws (referred to as contact models) that update the internal forces and moments. The time evolution of the system is computed via Newton's laws of motion. The particle flow code provides a synthetic material consisting of an assembly of rigid particles that interact at contacts, such as intact rock, jointed rock mass, and granular materials. 


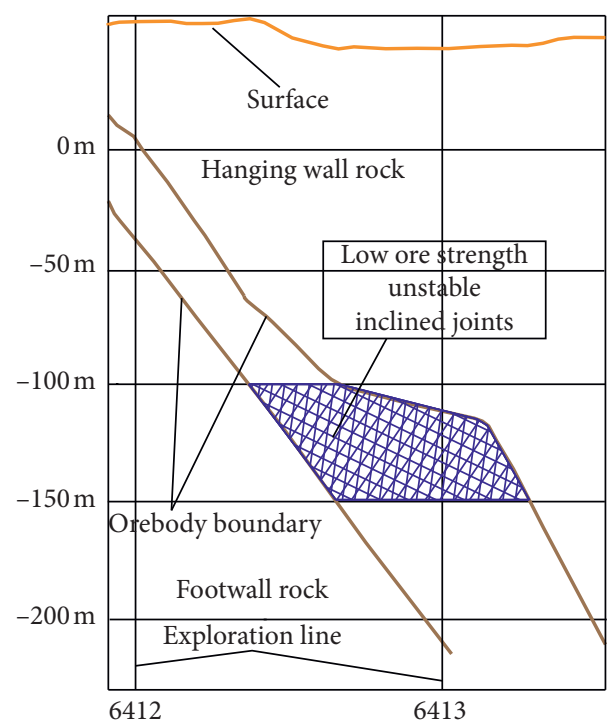

(a)

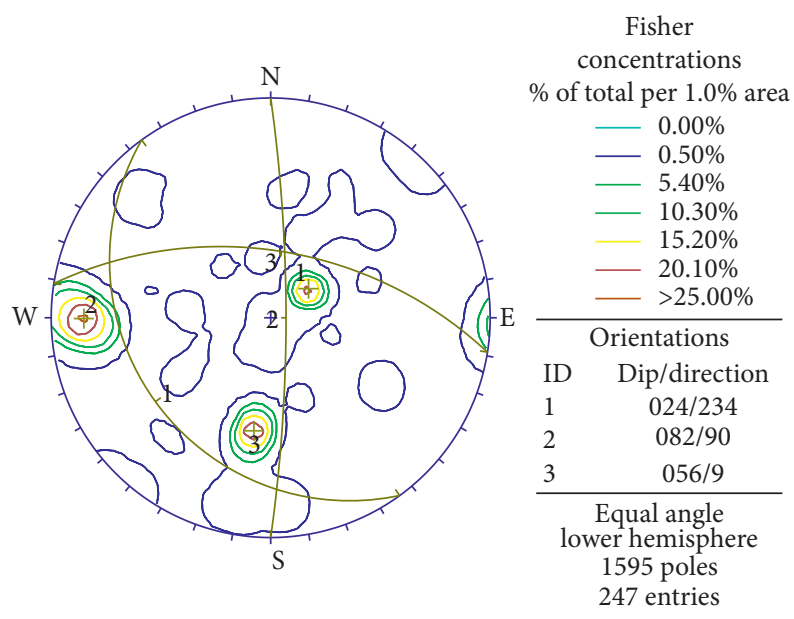

(b)

Figure 1: Orebody and inclined joints. (a) Orebody profile. (b) Contour plot of joints.

3.1. Synthetic Rock Mass (SRM). The particle flow code has been successfully used to study the mechanical properties or mechanical behavior of jointed rock mass [26-30] due to the development of the smooth-joint contact model [31]. The method has been termed the synthetic rock mass (SRM) methodology [25]. As shown in Figure 2, the modeling approach consists of joints (or discontinuities) information (discrete fracture network) in a bonded-particle model [32]. The bonded-particle model is used to represent the intact rock, and the mechanical behavior of the joint is introduced by modifying the contact models at the joint position.

In SRM modeling, two contact models need to be determined. One is the smooth-joint contact model used to represent the properties of joints, and the other is the bonded-particle model representing the properties of intact rock. First, the smooth-joint model simulates the behavior of a planar interface regardless of the local particle contact orientations along with the interface. As shown in Figure 2, the joint geometry consists of a planar interface separating two surfaces (surface 1 and surface 2). The behavior of a frictional or bonded joint can be modeled by assigning smooth-joint models to all contacts between particles that lie on opposite sides of the joint. Second, the flat-joint model is selected in the bonded-particle model. Because it can be applied to hard rock, and larger ratio of uniaxial compression strength to tensile strength can be obtained [33]. As shown in Figure 2, the flat-joint contact simulates the behavior of an interface between two notional surfaces (called faces), each of which is rigidly connected to a piece of a body [32]. In the flat-jointed model, the basic element is referred to as faced grains, each of which is depicted as a circular core and a number of skirted faces. Thus, faced grains can provide grain interlocking and rotational resistance even after the interface breaks [34]. An interface exists between each set of adjoining faces and is discretized into elements, with each element being either bonded or unbonded. The breakage of each bonded element contributes partial damage to the interface, and each breakage event is denoted as a crack [32].

3.2. Parameters of the Model. The microscopic parameters of a flat-jointed model could not be directly obtained from rock properties. The parameters needed to be calibrated by numerical tests, so that the numerical simulation results were consistent with the actual results. The calibration process for flat-jointed models was systematically introduced by several researchers $[25,34,35]$. In this paper, a large number of uniaxial compression and tensile numerical tests were carried out, and the calibration objectives of ore properties included the uniaxial compressive strength, tensile strength, Young's elastic modulus, and Poisson's ratio. The numerical tests performed for calibration are shown in Figure 3, and the microscopic parameters of the flat-jointed model are listed in Table 1 . The results show that rock properties are very close for those of the numerical model and those of magnetic ore. The flat-jointed model is appropriate, especially for a larger ratio of uniaxial compression strength to tensile strength.

The parameters of the joints also needed to be determined. Through field investigation in mine, the properties of joints were "FAIR" (smooth, moderately weathered, and altered surfaces) based on the chart for GSI estimates (modified by Cai et al. [36]). Under such conditions, Poulsen et al. [28] suggested that the joint friction coefficient was 0.5 and cohesive and tensile strengths were equal to 0 . These parameters were also suggested by Zhang et al. [37].

3.3. Model Design. In underground mining, the rock mass was subjected to vertical compressive stress and confining pressure. Therefore, the servo control method was used to exert pressure on the model. As shown in Figure 4, the vertical compressive stress is $4.96 \mathrm{MPa}$ and the confining pressure is $1.98 \mathrm{MPa}$ according to the in-situ stress of the 

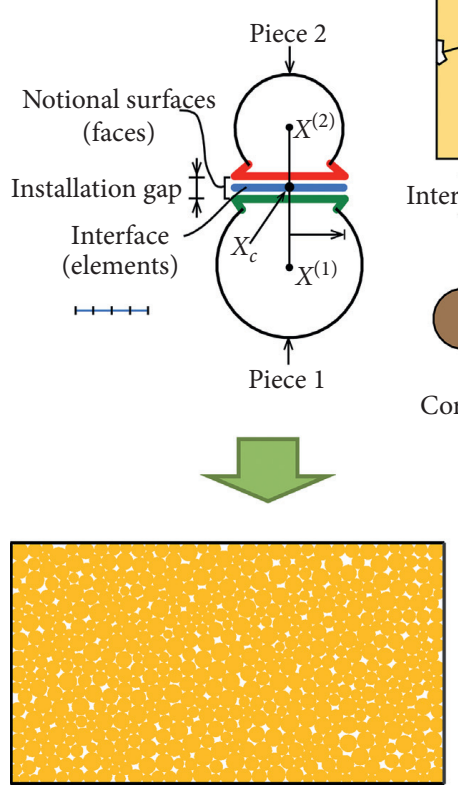

Flat-joint model
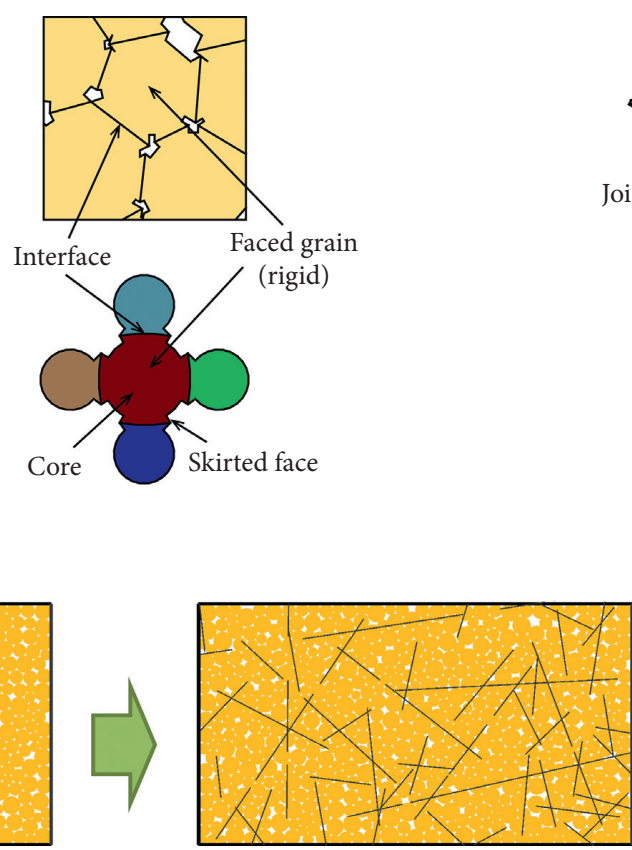

Synthetic rock mass (SRM)
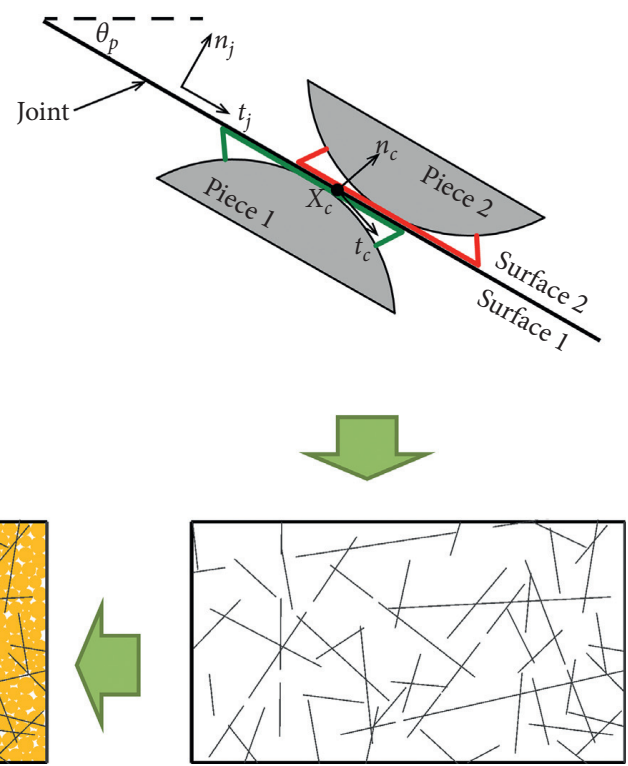

Smooth-joint model Discrete fracture network (DFN)

Figure 2: Synthetic rock mass (SRM) [25, 31, 32].

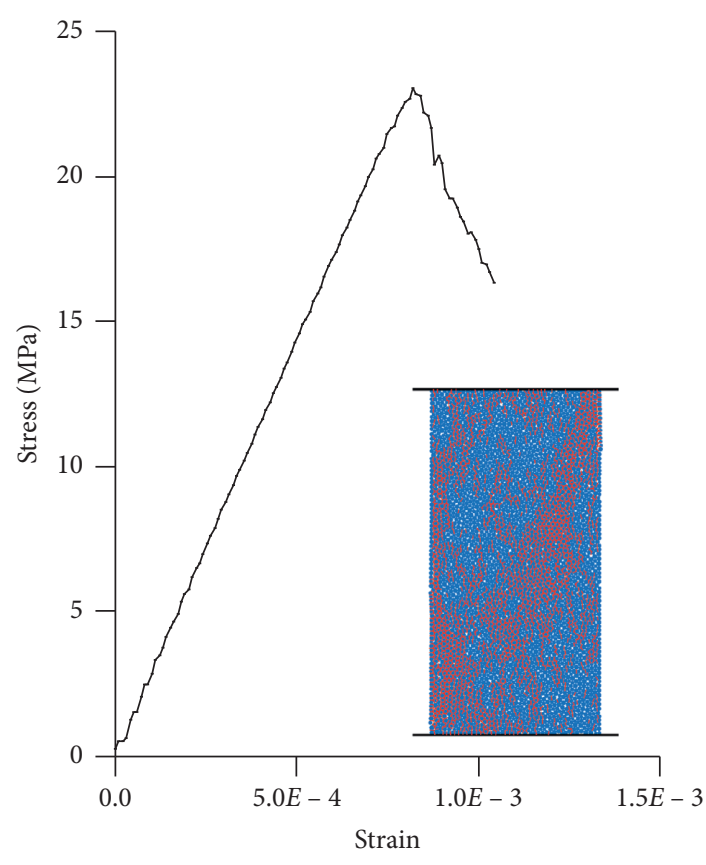

(a)

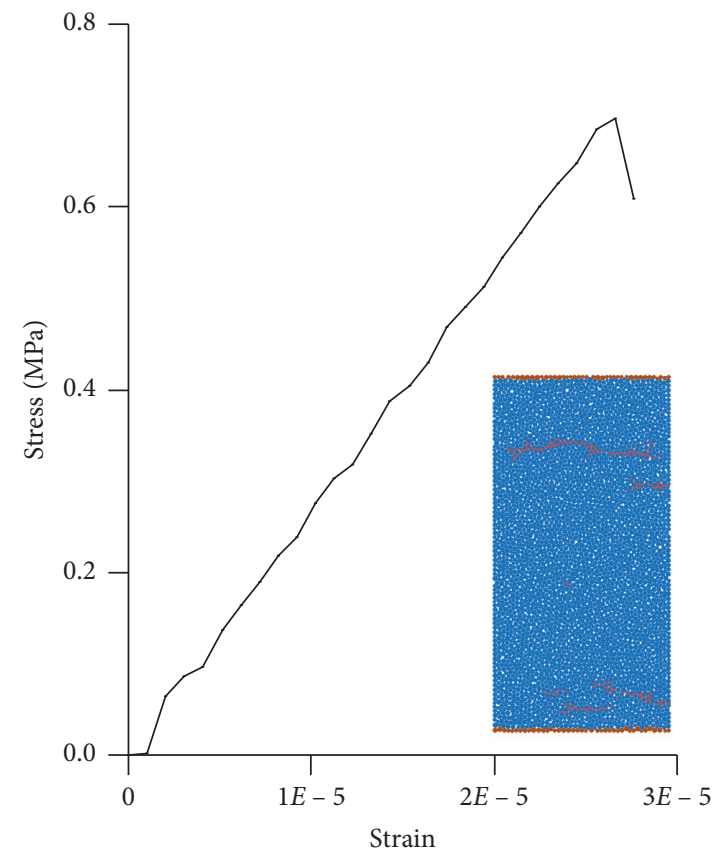

(b)

Figure 3: Numerical tests of the calibration parameters for the flat-jointed model. (a) Uniaxial compression test. (b) Tensile numerical test.

mine. The width of the model is $90 \mathrm{~m}$, and the height is $50 \mathrm{~m}$. The height of the undercut is $7 \mathrm{~m}$, the width of each undercut is $2 \mathrm{~m}$, and the total width of the undercut is $40 \mathrm{~m}$. The process of each undercut involves deleting the particles in the specified area $(2 \mathrm{~m} \times 7 \mathrm{~m})$ until the total undercut width reaches $40 \mathrm{~m}$. For the convenience of expression, the angle of the joint is redefined such that it refers to the angle between the undercut direction and the joint in the clockwise direction, as shown in Figure 4. It should be acknowledged that the caving particles from the model were deleted (by monitoring the velocity of the particles) to improve the calculation speed. 
TABLE 1: Calibrated parameters for the numerical model.

\begin{tabular}{|c|c|c|c|}
\hline & Description & Numerical model & Magnetic ore \\
\hline Particle-based properties & $\begin{array}{c}\text { Particle radius }(\mathrm{cm}) \\
\text { Particle density }\left(\mathrm{g} / \mathrm{cm}^{3}\right)\end{array}$ & $\begin{array}{c}10 \sim 15 \\
3.37\end{array}$ & \\
\hline Flat-jointed parameters & $\begin{array}{c}\text { Effective modulus }(\mathrm{GPa}) \\
\text { Normal-to-shear stiffness ratio } \\
\text { Friction angle }\left(^{\circ}\right) \\
\text { Friction coefficient } \\
\text { Tensile strength }(\mathrm{MPa}) \\
\text { Cohesion }(\mathrm{MPa})\end{array}$ & $\begin{array}{c}16.0 \\
0.24 \\
5.0 \\
0.5 \\
0.9 \\
16.5\end{array}$ & \\
\hline Rock properties & $\begin{array}{l}\text { Compressive strength }(\mathrm{MPa}) \\
\text { Young's elastic modulus }(\mathrm{GPa}) \\
\text { Poisson's ratio } \\
\text { Tensile strength }(\mathrm{MPa})\end{array}$ & $\begin{array}{c}23.20 \\
28.80 \\
0.26 \\
0.70\end{array}$ & $\begin{array}{c}22.61 \\
30.00 \\
0.25 \\
0.69\end{array}$ \\
\hline
\end{tabular}

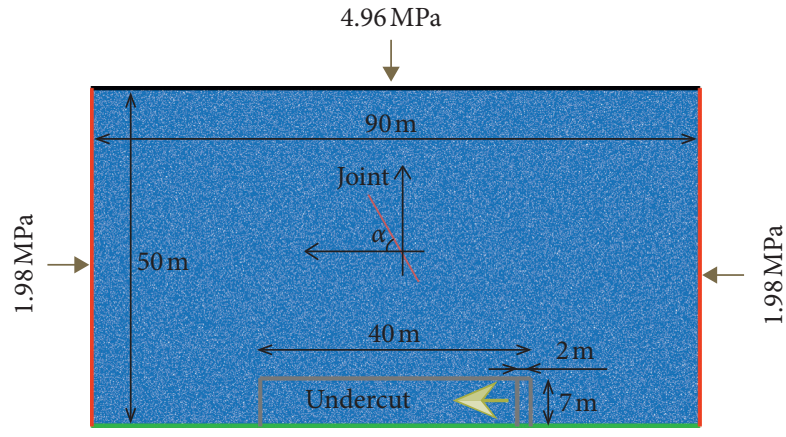

FIgURE 4: Design of the numerical model.

Another design involved adding joints in the model. According to the conditions of the Hemushan Iron Mine and the requirements for analysis and comparison, seven models were established based on the SRM model. The seven models are shown in Figure 5, and the parameters of each model are shown in Table 2 . The average density of the joint system is 3 per meter in model (e). Models (b), (c), and (d) are established by deleting the joint set in model (e). Models (f) and (g) are established by shortening the length of the joints in model (e). Models (a) to (d) are used to study the caving characteristics of rock mass with no joints and joint sets, models (b) to (e) are used to study the caving characteristics of rock mass with joint sets and joint systems, and models (e) to (g) are used to study the caving characteristics of rock mass with different joint lengths in the joint system.

\section{Numerical Simulation Results}

To determine the caving characteristics of a rock mass with inclined joints, the crack distribution, stress distribution, and caving line were monitored during the process of numerical simulation (undercut engineering).

4.1. Crack Distribution and Propagation. The SRM model was composed of bonded particles and joints, and the caving of the rock mass occurred as a result of undercutting. During the caving process, failure occurred in selected bonded contacts, and cracks were generated in the model. Therefore, the cracks were monitored during the different widths of the undercut, the results are shown in Figure 6, and red represents cracks.

In the model with no joints, as shown in Figure 6(a), cracks initially appear at the top of the undercut area and extend vertically. With the increase in the undercut width, the direction of crack propagation appears inclined, and then, they connect with each other and lead to the caving of the rock mass. Cracks mainly appear at the top of the undercut area.

The joint set models are shown in Figures 6(b)-6(d), and cracks initially appear around the undercut area. With the increase in the undercut width, the direction of crack propagation appears almost perpendicular or inclined to the joint direction, and then, they connect with each other or joints and lead to the caving of the rock mass. Cracks appear at the top of the undercut area, and the heights of the cracks are the highest at the top of the undercut area in the $98^{\circ}$ joint set model, but cracks also appear at the upper inclined ends on both sides of the undercut area in the $24^{\circ}$ and $124^{\circ}$ joint set model. Compared with a model with no joints, the joint set is favorable for the formation of cracks, and the $124^{\circ}$ joint set is obvious for the Hemushan Iron Mine.

Joint system models are shown in Figures 6(e)-6(g), and cracks initially appear around the undercut area. With the increase in the undercut width, the direction of crack propagation is inclined to the joint direction, and then, they connect with each other or joints and lead to the caving of the rock mass. With decreasing joint length, the number of cracks decreases under the same width of the undercut. Cracks appear at the top of the undercut area and the upper inclined ends on both sides of the undercut area.

4.2. Stress Distribution. The contact force between particles could be determined by the particle flow code, and the stress distribution and stress concentration area could be determined by the contact force. In the process of numerical simulation, the contact forces were determined during the different widths of the undercut. The results are shown in Figure 7.

The model with no joints is shown in Figure 7(a). The stress concentration areas are mainly distributed in the upper two corners of the rectangular undercut area. With the increase in the undercut width, stress concentration areas also appear on the sides of the undercut area, especially when 


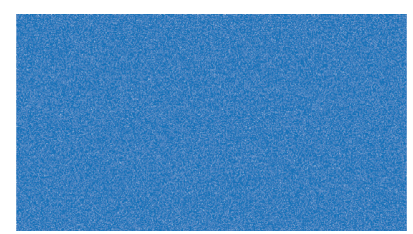

(a)

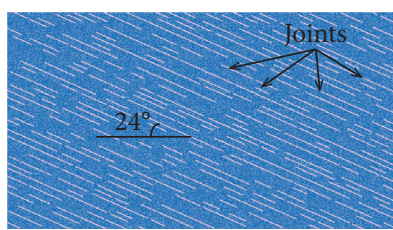

(b)

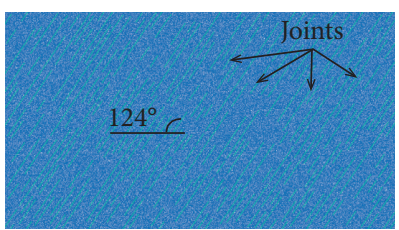

(c)

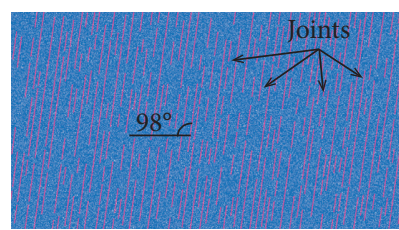

(d)

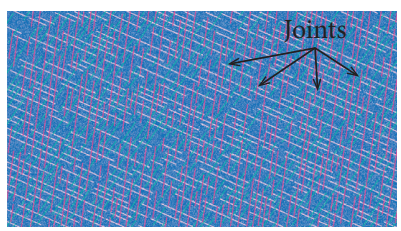

(e)

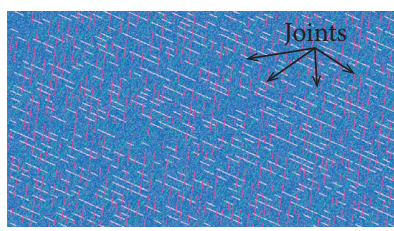

(f)

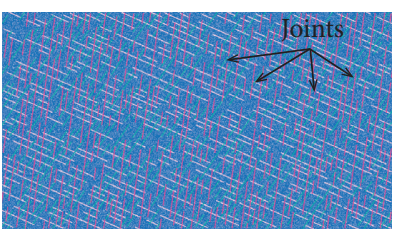

(g)

Figure 5: Numerical models. (a) No joints. (b) $24^{\circ}$ joint set. (c) $124^{\circ}$ joint set. (d) $98^{\circ}$ joint set. (e) Joint system 1. (f) Joint system 2. (g) Joint system 3.

TABLE 2: Joint parameters of the numerical model.

\begin{tabular}{|c|c|c|c|}
\hline \multicolumn{2}{|c|}{ Model } & \multicolumn{2}{|c|}{ Joint } \\
\hline Number & Description & Angle & Length \\
\hline $\mathrm{a}$ & No joints & & \\
\hline $\mathrm{b}$ & $24^{\circ}$ joint set & $24^{\circ}$ & $3 \sim 25 \mathrm{~m}$ \\
\hline c & $124^{\circ}$ joint set & $124^{\circ}$ & $3 \sim 25 \mathrm{~m}$ \\
\hline d & $98^{\circ}$ joint set & $98^{\circ}$ (steep-dip) & $3 \sim 25 \mathrm{~m}$ \\
\hline e & Joint system 1 & $24^{\circ}, 124^{\circ}, 98^{\circ}$ & $3 \sim 25 \mathrm{~m}$ \\
\hline $\mathrm{f}$ & Joint system 2 & $24^{\circ}, 124^{\circ}, 98^{\circ}$ & $1.5 \sim 12.5 \mathrm{~m}$ \\
\hline g & Joint system 3 & $24^{\circ}, 124^{\circ}, 98^{\circ}$ & $2.4 \sim 20 \mathrm{~m}$ \\
\hline
\end{tabular}
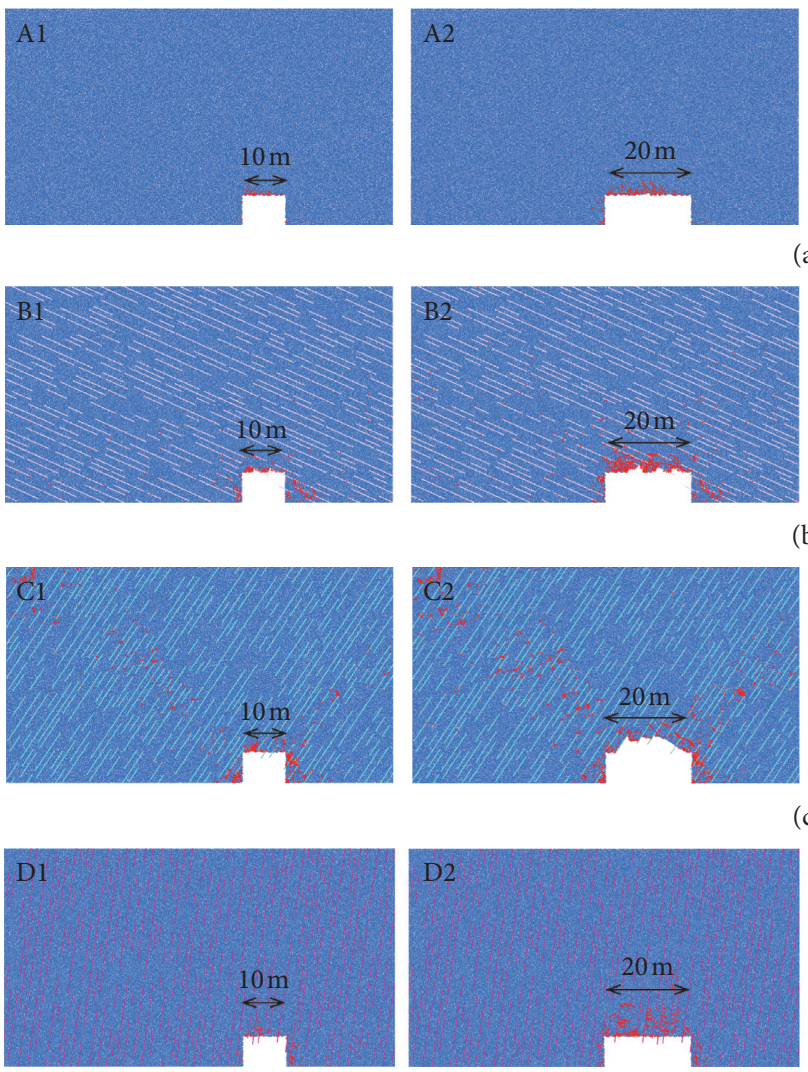
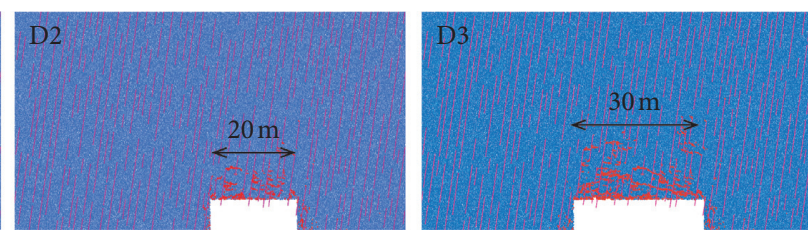

(d)

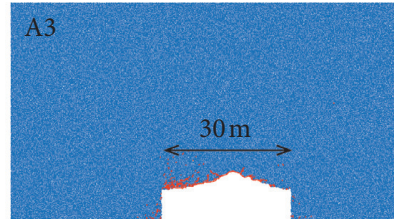

(a)

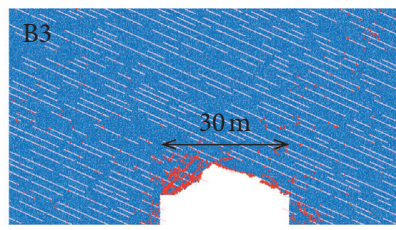

(b)

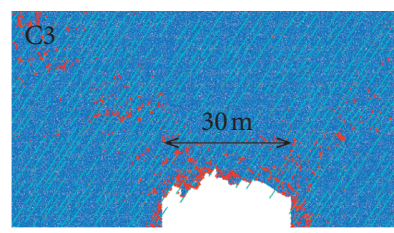

(c)
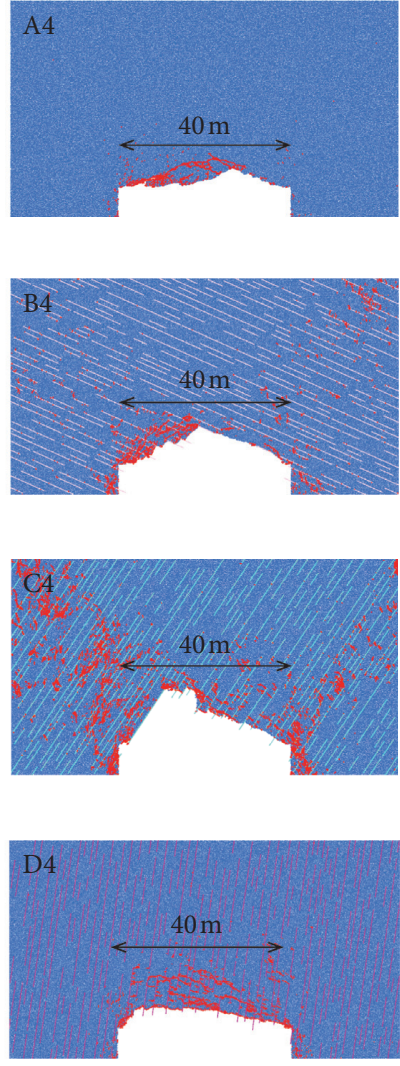

Figure 6: Continued. 

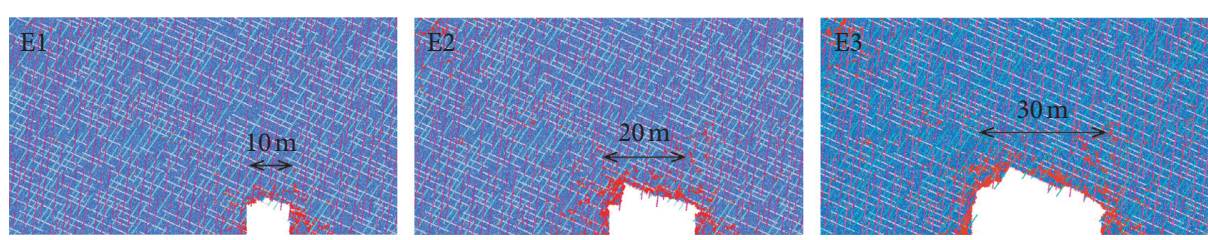

(e)
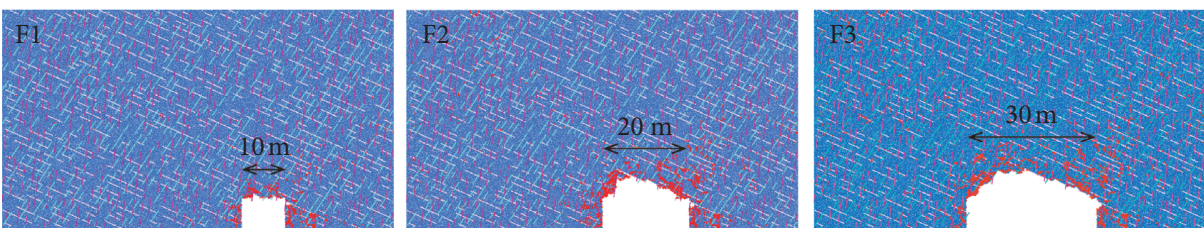

(f)
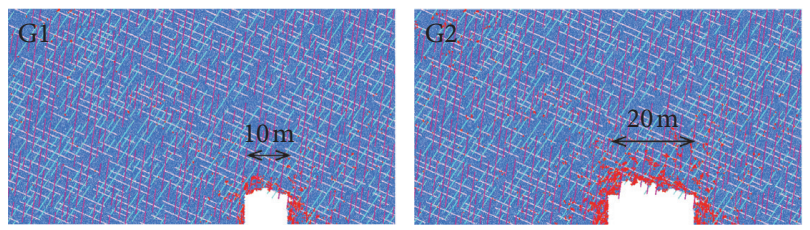
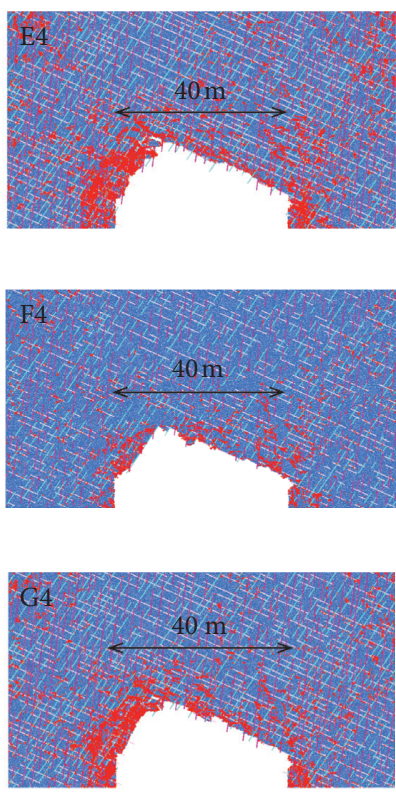

(g)

Figure 6: Crack propagation of the seven models. (a) No joints. (b) $24^{\circ}$ joint set. (c) $124^{\circ}$ joint set. (d) $98^{\circ}$ joint set. (e) Joint system 1 . (f) Joint system 2. (g) Joint system 3.
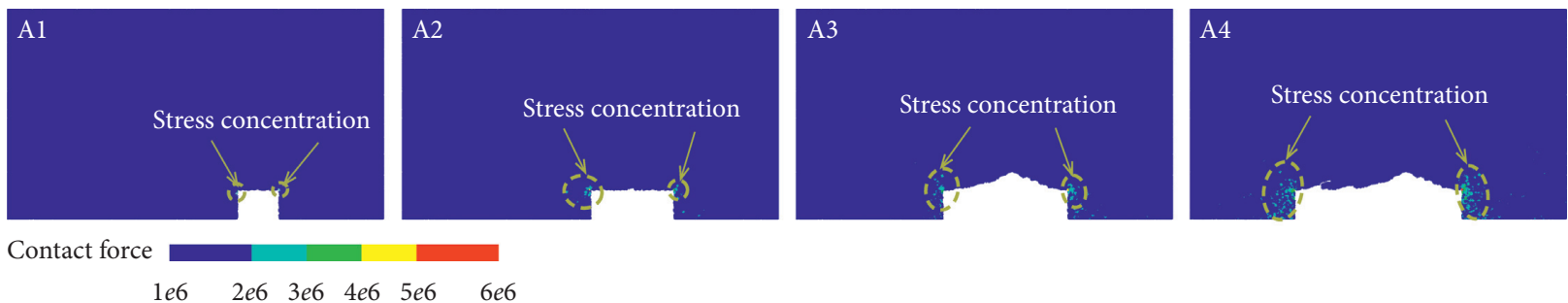

(a)
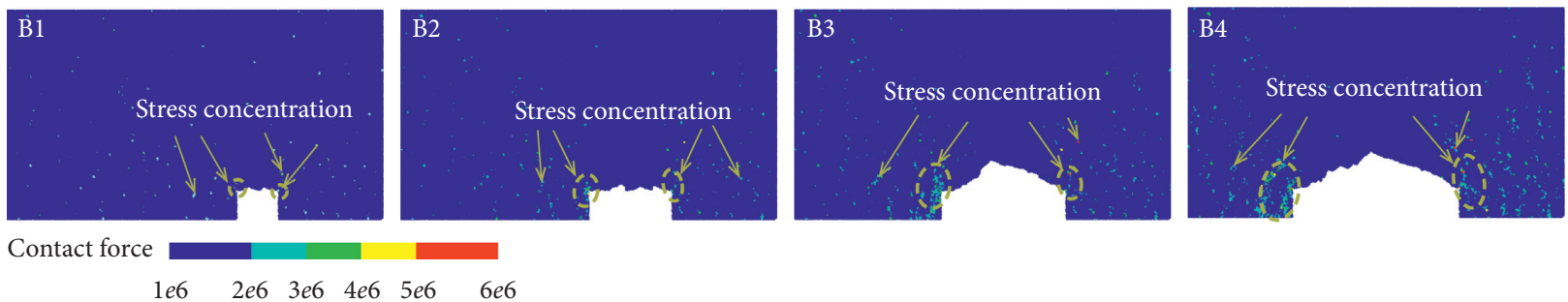

(b)
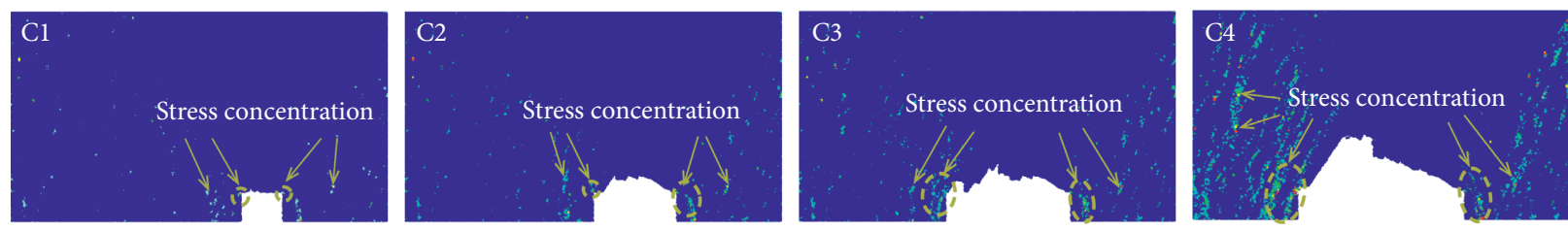

$\begin{array}{rrrrr}\text { Contact force } & & & & \end{array}$

(c)

Figure 7: Continued. 

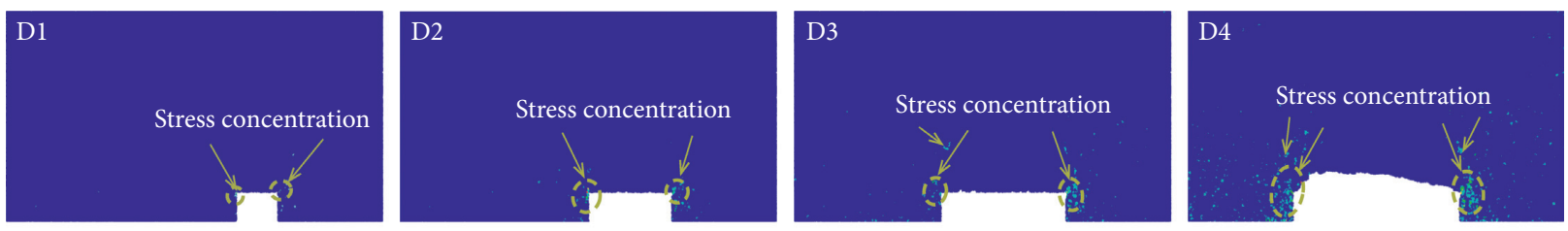

Contact force

$1 e 6 \quad 2 e 6 \quad 3 e 6 \quad 4 e 6 \quad 5 e 6 \quad 6 e 6$

(d)
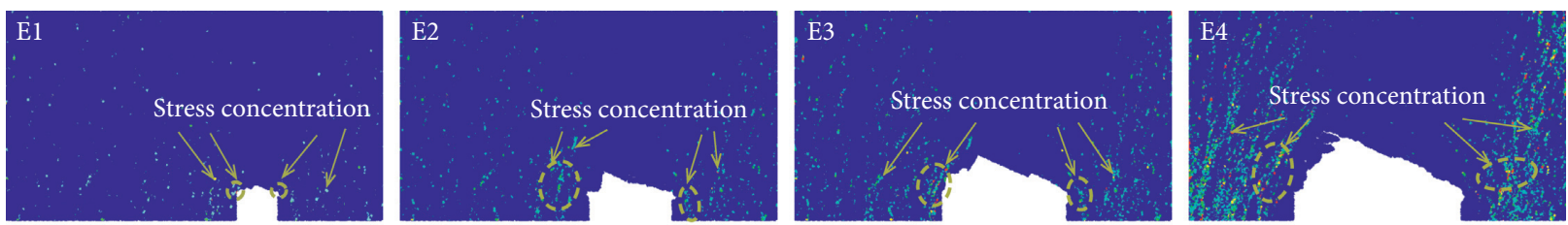

Contact force

$1 e 6 \quad 2 e 6 \quad 3 e 6 \quad 4 e 6 \quad 5 e 6 \quad 6 e 6$

(e)
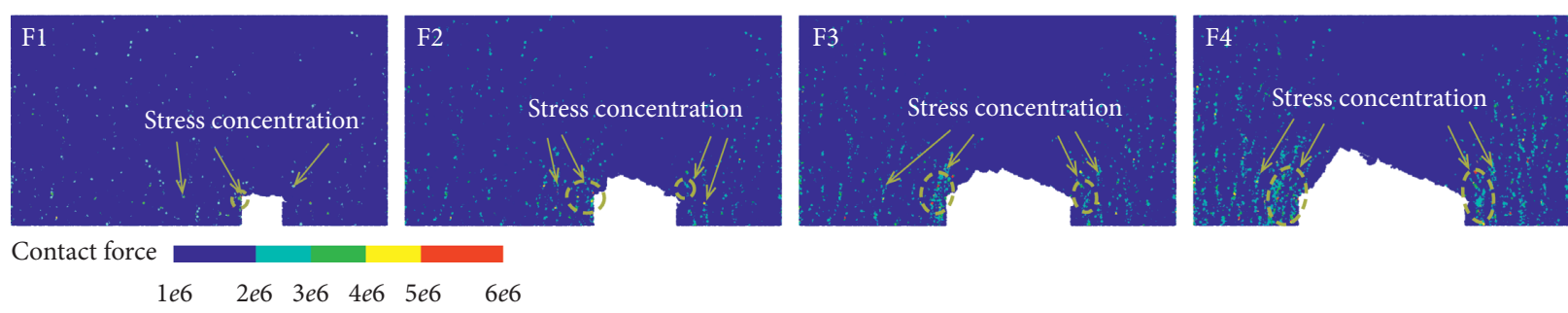

(f)
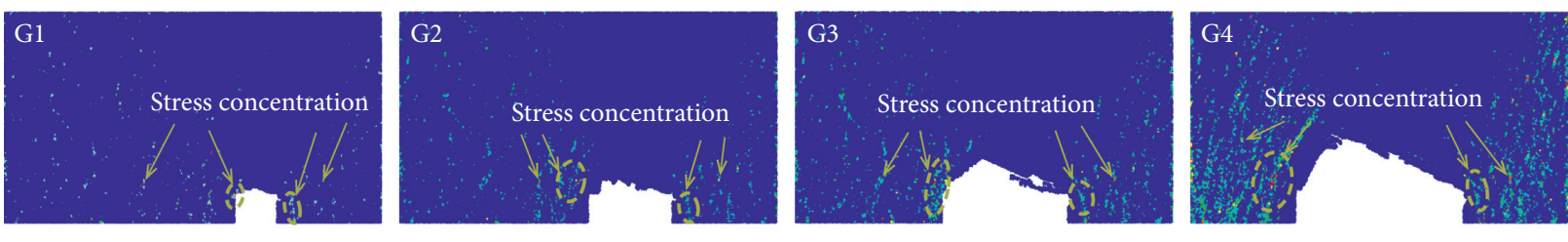

Contact force

$1 e 6 \quad 2 e 6 \quad 3 e 6 \quad 4 e 6 \quad 5 e 6 \quad 6 e 6$

(g)

Figure 7: Stress distribution of the seven models. (a) No joints. (b) $24^{\circ}$ joint set. (c) $124^{\circ}$ joint set. (d) $98^{\circ}$ joint set. (e) Joint system 1 . (f) Joint system 2. (g) Joint system 3.

the width of the undercut is $40 \mathrm{~m}$. However, the stress concentration areas are mainly distributed around the undercut area. Joint set models are shown in Figures 7(b)-7(d). The stress concentration areas are distributed in the upper two corners of the rectangular undercut area, but they also appear in other areas in the models except for the top of the undercut area. With the increase in the undercut width, the stress concentration areas on both sides of the undercut area are significant. The joint system models are shown in Figures $7(\mathrm{e})-7(\mathrm{~g})$, and the stress concentration areas are similar to those of the joint set models. With decreasing joint length, the degree of stress concentration becomes weaker under the same width of the undercut.

4.3. Caving Line. The caving line is also known as the caving arch because the shape of the caving line is usually considered to be an arch. In the process of numerical simulation, caving lines are drawn for the different widths of the undercut, and the results are shown in Figure 8.

In the no joints model, as shown in Figure 8(a), the highest point of the caving line is basically located in the middle of the undercut width, and the angle between the caving line and the horizontal direction is small. The joint set models are shown in Figures $8(\mathrm{~b})-8(\mathrm{~d})$. The highest point of the caving line is biased towards the direction of the undercut, and the angle between the caving line and the horizontal direction is larger than that of the model with no joints. The joint system models are shown in Figures 8(e)$8(\mathrm{~g})$. The highest point of the caving line is also biased towards the direction of the undercut, and the angle between the caving line and the horizontal direction is larger than that of the model with no joints and that of the joint set models. With decreasing joint length, the height of the caving line decreases under the same width of the undercut. 


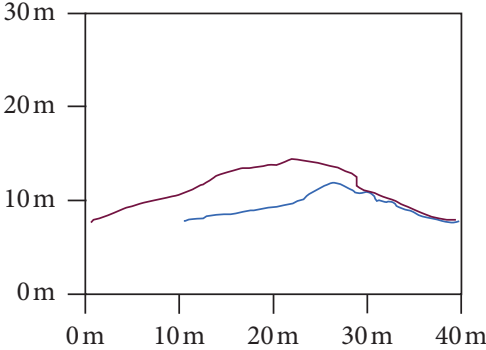

(a)

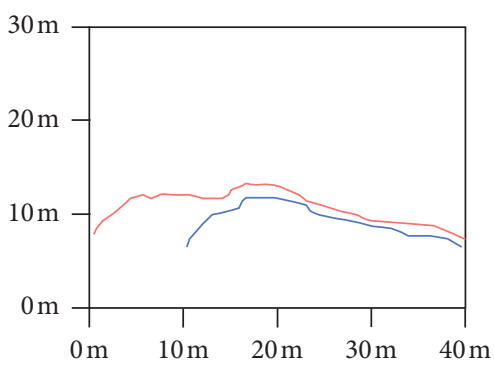

(d)

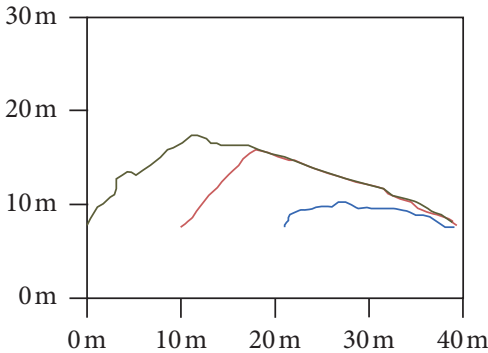

(b)

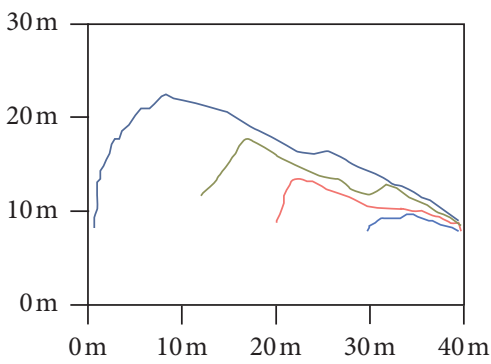

(e)

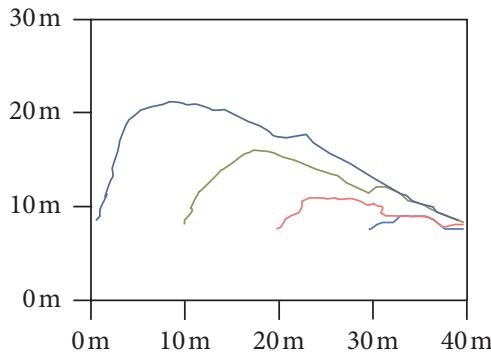

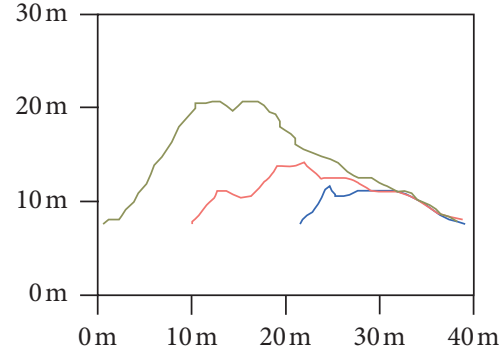

(c)

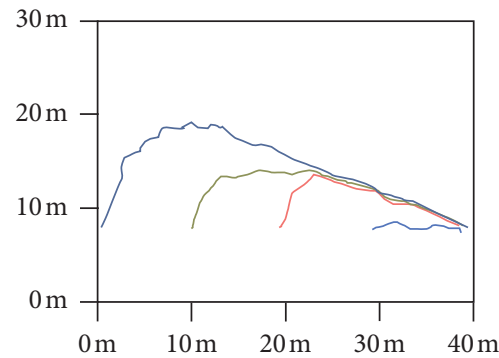

(f)

(g)

FIGURE 8: Caving line of the seven models. (a) No joints. (b) $24^{\circ}$ joint set. (c) $124^{\circ}$ joint set. (d) $98^{\circ}$ joint set. (e) Joint system 1 . (f) Joint system 2. (g) Joint system 3.

\section{Discussion}

Based on the simulation results of seven numerical models, the caving characteristics of the model with no jointed rock mass and the model with an inclined rock mass can be analyzed.

The caving characteristics of rock masses with no joints were simple, but caving mining was difficult. The crack zone mainly appeared at the top of the undercut area, the stress concentration areas were mainly distributed in the upper two corners of the rectangular undercut area, and the caving line could be simplified as an arch. It could be concluded that joints had an important influence on the caving characteristics.

The caving characteristics of rock mass with joint sets or joint systems are complicated, but they are beneficial for caving mining. The caving characteristics were as follows:

(1) Crack zone and propagation: an obvious crack zone existed in the inclined jointed rock mass after undercutting. The distribution of the crack zone was related to the undercut width, the dip angle of the joint set, and the joint length in the joint system.
With the increase in the undercut width, the crack zone not only existed around the undercut area but also existed further away in the model (such as in the upper inclined ends on both sides of the undercut area). The direction of crack propagation was inclined to the joint direction, and then, the cracks connected with each other or the joints, which led to the caving of the rock mass. With the decrease in the joint length in the joint system, the number of cracks decreased under the same undercut width.

(2) Stress distribution: with the increase in the undercut width in the inclined jointed rock mass, the stress concentration areas were not only distributed in the upper two corners of the rectangular undercut area but also distributed in other areas in the models except the top of the undercut area. With decreasing joint length, the degree of stress concentration became weaker under the same width of the undercut.

(3) Caving line: the caving line in the inclined jointed rock mass was not a standard arch. With the increase in the undercut width, the highest point of the caving line was biased towards the direction of the undercut, 


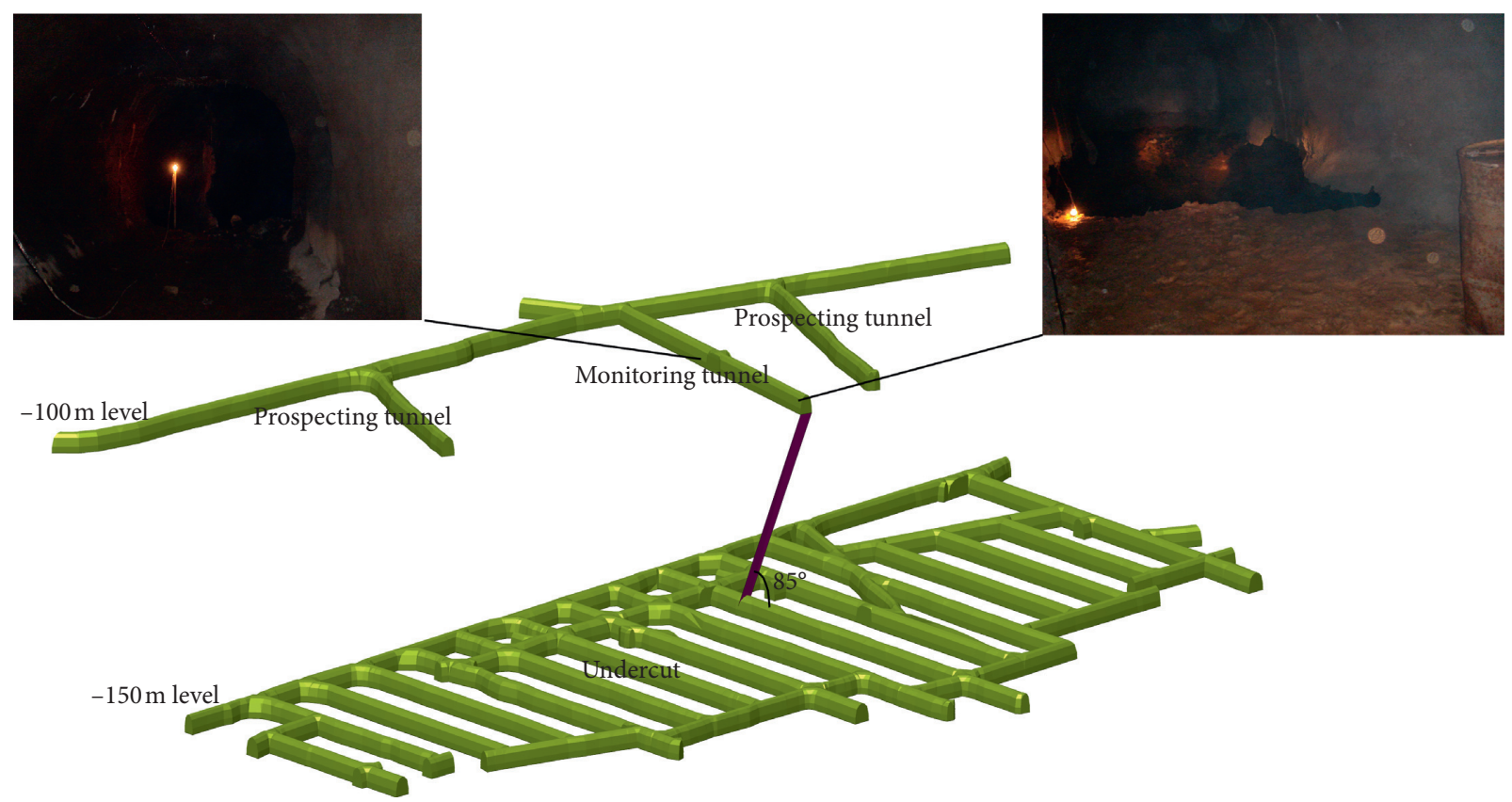

FIGURE 9: Monitoring of caving mining.

and the angle between the caving line and the horizontal direction was related to the conditions of the joint. For the rock mass of the joint system in this paper, one side of the caving line was very steep (Figures $8(\mathrm{e})-8(\mathrm{~g})$ ), and the angle between the caving line and the horizontal direction reached more than $80^{\circ}$. In actual mining, the monitoring tunnel was set up to monitor the caving process (Figure 9), and the results showed that the angle between the caving line and the horizontal direction reached $85^{\circ}$. With the decrease in joint length, the height of the caving line decreased under the same width of the undercut.

It should be noted that the caving of a rock mass with a steeply dipping joint set (such as the $98^{\circ}$ joint set in this paper) was difficult in the early stage of mining. However, a large number of cracks existed above the undercut area (Figure 6(d)). With the continuous increase in the undercut width, the number of cracks also increased, and then, they connected with each other or joints, which led to the caving of the rock mass. In this situation, the amount of rock mass that caved was very large, which would threaten miners, mining equipment, mining facilities, etc. Protection or treatment measures, such as increasing the height of the blasted orebody during undercut engineering and using the blasting ore as the overburden or using hydraulic fracturing to promote caving of the rock mass in the early stage of mining, are necessary for the safety mining of mine.

\section{Conclusions}

In this study, the caving characteristics of rock mass with inclined joints in caving mining were investigated. For this purpose, seven numerical models were established based on the SRM model and the conditions of the Hemushan Iron Mine.
The crack distribution, stress distribution, and caving line were determined for rock mass with different joint conditions, and the joint conditions included no joints, joint sets, and joint systems. The main conclusions for the caving characteristics of rock mass with inclined joints were as follows:

(1) In the caving process, the crack zone was significant, and it not only existed around the undercut area but also existed further away in the model. The distribution of the crack zone was related to the undercut width, the dip angle of the joint set, and the joint length in the joint system.

(2) The stress concentration areas not only existed in the upper two corners of the rectangular undercut area (or arch corner) but also dispersed elsewhere in the model except for the top of the undercut area.

(3) The caving line was not a standard arch, and the highest point of the caving line was biased towards the direction of the undercut.

(4) The joint length had an influence on the caving characteristics of rock mass with inclined joints. Under the same undercut width, with the decrease in the joint length in the joint system, the number of cracks decreased, the degree of stress concentration became weaker, and the height of the caving line decreased.

\section{Data Availability}

The data used to support the findings of this study are included within the article.

\section{Conflicts of Interest}

The authors declare that they have no conflicts of interest. 


\section{Acknowledgments}

This study was jointly supported by grants from the National Key Research and Development Program of China (Grant no. 2016YFC0801601) and the Key Program of the National Natural Science Foundation of China (Grant no. 51534003). The authors are grateful for the support.

\section{References}

[1] D. H. Laubscher, "Cave mining-the state of the art," The Journal of the South African Institute of Mining and Metallurgy, vol. 94, no. 10, pp. 279-293, 1994.

[2] E. T. Brown, Block Caving Geomechanics, Julius Kruttschnitt Mineral Research Center, Indooroopilly, Australia, 2003.

[3] F. Kendorski, "The cavability of ore deposits," Min. Engng.vol. 30, no. 6, pp. 628-631, 1978.

[4] P. Duplancic and B. H. Brady, "Characterisation of caving mechanisms by analysis of seismicity and rock stress," in Proceedings of the 9th International Congress on Rock Mechanics, G. Vouille and P. Berest, Eds., International Society for Rock Mechanics and Rock Engineering, Paris, France, pp. 1049-1453, August 1999.

[5] D. Cumming-Potvin, J. Wesseloo, S. W. Jacobsz, and E. Kearsley, "Fracture banding in caving mines," Journal of the Southern African Institute of Mining and Metallurgy, vol. 116, no. 8, pp. 753-761, 2016.

[6] Z. Jiang and B. Yang, "Numerical simulation of caving law in natural caving mining method based on deformable discrete element method," Rock and Soil Mechanics, vol. 26, no. 2, pp. 239-242, 2005.

[7] W. Song, J. Du, X. Yin, and G. Tang, "Caving mechanism of hangingwall rock and rules of surface subsidence due to nopillar sub-level caving method in an iron mine," Journal of China Coal Society, vol. 35, no. 7, pp. 1078-1083, 2010.

[8] G. Zhang and X. Zhao, "Numerical simulation on induced caving of rock mass," Journal of Northeastern University, vol. 33, no. 8, pp. 1190-1193, 2012.

[9] G. Cheng, T. Ma, C. Tang, H. Liu, and S. Wang, "A zoning model for coal mining-induced strata movement based on microseismic monitoring," International Journal of Rock Mechanics and Mining Sciences, vol. 94, pp. 123-138, 2017.

[10] Y. Zhao, T. Yang, M. Bohnhoff et al., "Study of the rock mass failure process and mechanisms during the transformation from open-pit to underground mining based on microseismic monitoring," Rock Mechanics and Rock Engineering, vol. 51, no. 5, pp. 1473-1493, 2018.

[11] M. Ju, X. Li, Q. Yao, S. Liu, S. Liang, and X. Wang, "Effect of sand grain size on simulated mining-induced overburden failure in physical model tests," Engineering Geology, vol. 226, pp. 93-106, 2017.

[12] B. Ghabraie, G. Ren, and J. V. Smith, "Characterising the multi-seam subsidence due to varying mining configuration, insights from physical modelling," International Journal of Rock Mechanics and Mining Sciences, vol. 93, pp. 269-279, 2017.

[13] D. Huayang, L. Xugang, L. Jiyan et al., "Model study of deformation induced by fully mechanized caving below a thick loess layer," International Journal of Rock Mechanics and Mining Sciences, vol. 47, no. 6, pp. 1027-1033, 2010.

[14] J.-a. Wang, J. Tang, and S.-h. Jiao, "Seepage prevention of mining-disturbed riverbed," International Journal of Rock Mechanics and Mining Sciences, vol. 75, pp. 1-14, 2015.
[15] F. H. Hassen, L. Spinnler, and J. Fine, "A new approach for rock mass cavability modeling," International Journal of Rock Mechanics and Mining Sciences \& Geomechanics Abstracts, vol. 30, no. 7, pp. 1379-1385, 1993.

[16] A. Vyazmensky, D. Stead, D. Elmo, and A. Moss, "Numerical analysis of block caving-induced instability in large open pit slopes: a finite element/discrete element approach," Rock Mechanics and Rock Engineering, vol. 43, no. 1, pp. 21-39, 2009.

[17] A. Vakili and B. K. Hebblewhite, "A new cavability assessment criterion for longwall top coal caving," International Journal of Rock Mechanics and Mining Sciences, vol. 47, no. 8, pp. 1317-1329, 2010.

[18] L. C. Li, C. A. Tang, X. D. Zhao, and M. Cai, "Block cavinginduced strata movement and associated surface subsidence: a numerical study based on a demonstration model," Bulletin of Engineering Geology and the Environment, vol. 73, no. 4, pp. 1165-1182, 2014.

[19] S. Cao, W. Song, D. Deng, Y. Lei, and J. Lan, "Numerical simulation of land subsidence and verification of its character for an iron mine using sublevel caving," International Journal of Mining Science and Technology, vol. 26, no. 2, pp. 327-332, 2016.

[20] A. Paluszny and R. W. Zimmerman, "Modelling of primary fragmentation in block caving mines using a finite-element based fracture mechanics approach," Geomechanics and Geophysics for Geo-Energy and Geo-Resources, vol. 3, no. 2, pp. 121-130, 2017.

[21] R. Rafiee, M. Ataei, R. KhalooKakaie, S. E. Jalali, F. Sereshki, and M. Noroozi, "Numerical modeling of influence parameters in cavabililty of rock mass in block caving mines," International Journal of Rock Mechanics and Mining Sciences, vol. 105, pp. 22-27, 2018.

[22] F. Ren, D. Zhang, J. Cao, M. Yu, and S. Li, "Study on the rock mass caving and surface subsidence mechanism based on an in situ geological investigation and numerical analysis," Mathematical Problems in Engineering, vol. 2018, Article ID 6054145, 18 pages, 2018.

[23] M. Eremin, G. Esterhuizen, and I. Smolin, "Numerical simulation of roof cavings in several Kuzbass mines using finitedifference continuum damage mechanics approach," International Journal of Mining Science and Technology, vol. 30, no. 2, pp. 157-166, 2020.

[24] D. H. Laubscher, "A geomechanics classification system for the rating of rock mass in mine design," Journal of the Southern African Institute of Mining and Metallurgy, vol. 90, no. 10, pp. 257-273, 1990.

[25] Itasca Consulting Group, PFC Version5.0 User's Manual, Itasca Consulting Group, Minneapolis, MN, USA, 2017.

[26] Y. Zhang, X. Liu, T. Yang, P. Jia, X. Liu, and F. Ren, "A 3D synthetic rock mass numerical method for characterizations of rock mass and excavation damage zone near tunnels," Bulletin of Engineering Geology and the Environment, vol. 70, no. 2, pp. 5615-5629, 2020.

[27] D. Mas Ivars, M. E. Pierce, C. Darcel et al., "The synthetic rock mass approach for jointed rock mass modelling," International Journal of Rock Mechanics and Mining Sciences, vol. 48, no. 2, pp. 219-244, 2011.

[28] B. A. Poulsen, D. P. Adhikary, M. K. Elmouttie, and A. Wilkins, "Convergence of synthetic rock mass modelling and the Hoek-Brown strength criterion," International Journal of Rock Mechanics and Mining Sciences, vol. 80, pp. 171-180, 2015. 
[29] J. A. Vallejos, K. Suzuki, A. Brzovic, and D. M. Ivars, "Application of synthetic rock mass modeling to veined core-size samples," International Journal of Rock Mechanics and Mining Sciences, vol. 81, pp. 47-61, 2016.

[30] X. Yang, P. H. S. W. Kulatilake, H. Jing, and S. Yang, "Numerical simulation of a jointed rock block mechanical behavior adjacent to an underground excavation and comparison with physical model test results," Tunnelling and Underground Space Technology, vol. 50, pp. 129-142, 2015.

[31] M. E. Pierce and C. Fairhurst, "Synthetic rock mass applications in mass mining," in Harmonising Rock Engineering and the Environment, Q. Qian and Y. Zhou, Eds., pp. 109-114, Taylor \& Francis Group, London, UK, 2012.

[32] D. O. Potyondy, "The bonded-particle model as a tool for rock mechanics research and application: current trends and future directions," Geosystem Engineering, vol. 18, no. 1, pp. 1-28, 2015.

[33] F. Ren, H. Liu, R. He, G. Li, and Y. Liu, "Point load test of halfcylinder core using the numerical model and laboratory tests: size suggestion and correlation with cylinder core," Advances in Civil Engineering, vol. 2018, Article ID 3870583, 11 pages, 2018.

[34] S. Wu and X. Xu, "A study of three intrinsic problems of the classic discrete element method using flat-joint model," Rock Mechanics and Rock Engineering, vol. 49, no. 5, pp. 1813-1830, 2015.

[35] K. Li, Y. Cheng, and X. Fan, "Roles of model size and particle size distribution on macro-mechanical properties of Lac du Bonnet granite using flat-joint model," Computers and Geotechnics, vol. 103, pp. 43-60, 2018.

[36] M. Cai, P. K. Kaiser, H. Uno, Y. Tasaka, and M. Minami, "Estimation of rock mass deformation modulus and strength of jointed hard rock masses using the GSI system," International Journal of Rock Mechanics and Mining Sciences, vol. 41, no. 1, pp. 3-19, 2004.

[37] Y. Zhang, F. Y. Ren, T. H. Yang, S. Y. Wang, W. F. Zhang, and M. X. Yu, "An improved rock mass characterization method using a quantified geological strength index and synthetic rock mass model," Rock Mechanics and Rock Engineering, vol. 51, no. 11, pp. 3521-3536, 2018. 